\title{
Functional dissection of hnRNP D suggests that nuclear import is required before hnRNP D can modulate mRNA turnover in the cytoplasm
}

\author{
CHYI-YING A. CHEN, ${ }^{1}$ NIANHUA XU, ${ }^{1,2}$ WENMIAO ZHU, ${ }^{1}$ and ANN-BIN SHYU ${ }^{1}$ \\ ${ }^{1}$ Department of Biochemistry and Molecular Biology, The University of Texas Medical School at Houston, Houston, Texas 77030, USA
}

\begin{abstract}
Many shuttling proteins not only function in the nucleus but also control mRNA fates in the cytoplasm. We test whether a link exists between their nuclear association with mRNPs and their cytoplasmic functions using the p37 isoform of hnRNP D, which inhibits the rapid cytoplasmic mRNA decay in NIH3T3 cells. We showed that p37 shuttles between nucleus and cytoplasm, and narrowed down the nuclear import signal to a 50-amino-acid C-terminal domain. A p37 mutant missing this domain, still capable of associating with target mRNAs in vitro, was confined to the cytoplasm, where it was unable to block cytoplasmic mRNA turnover. Introducing heterologous shuttling domains to this mutant, thereby restoring its ability to enter the nucleus, concomitantly restored its cytoplasmic function. Association of p37 with its target mRNAs can only be detected when it can enter the nucleus. Our results suggest that nuclear import of hnRNP D is a prerequisite for it to exert its cytoplasmic function. This study provides a useful model system to elucidate the mechanisms by which "nuclear history" affects cytoplasmic mRNA fates.
\end{abstract}

Keywords: AUF1; ARE; hnRNP D; nuclear-cytoplasmic shuttling; RNA turnover

\section{INTRODUCTION}

Genes are transcribed into premessenger RNAs that undergo a series of processing steps in the nucleus. Mature mRNAs are then exported to the cytoplasm, where they become associated with specific subcellular compartments, are translated into protein, and are degraded at rates dictated by transcript- and cell-type-specific cues. It has become increasingly clear that the nuclear history of each mRNA, including its transcription, 3 '-end formation, splicing, and export, influences the cytoplasmic fate of the mRNA (for reviews, see Wolffe and Meric 1996; Shyu and Wilkinson 2000; Kim and Dreyfuss 2001; Maniatis and Reed 2002; Dreyfuss et al. 2003; Le Hir et al. 2003).

Two prominent examples that illustrate the interconnection of nuclear history and cytoplasmic fate of mRNA are the RNA splicing-coupled translation control and non-

Reprint requests to: Ann-Bin Shyu, Department of Biochemistry and Molecular Biology, The University of Texas Medical School at Houston, Houston, Texas 77030, USA; e-mail address: Ann-Bin.Shyu@uth.tmc.edu; fax: (713) 500-0575.

Present address: ${ }^{2}$ Lexicon Genetics, The Woodlands, Texas 77384, USA.

Article and publication are at http://www.rnajournal.org/cgi/doi/ 10.1261/rna.5269304. sense-codon-mediated mRNA decay (NMD). In both cases, the fate of mRNAs in the cytoplasm, whether destined for translation or degradation, appears predetermined in the nucleus during the process of RNA splicing. Earlier studies using Xenopus oocyte as a model system showed that translational repression or activation of maternal mRNAs depends on whether the transcripts have gone through RNA splicing in the nucleus or not; spliced intron sequences also greatly affected the translational fate of maternal mRNAs (Matsumoto and Wolffe 1998; Matsumoto et al. 1998). Recent studies extended these observations to plants and mammalian cells and showed that splicing has a significant effect on translational utilization of the corresponding mRNA (Bourdon et al. 2001; Lu and Cullen 2003; Nott et al. 2003). The level of the effects, whether positive or negative, depends on the identity, position, and exon sequence context of the introns involved (for review, see Le Hir et al. 2003). In the case of NMD, it is sometimes the cytoplasmic turnover fate of premature termination codon (PTC)-containing mRNA that is affected by RNA splicing (Hentze and Kulozik 1999; Maquat and Carmichael 2001; Wilusz et al. 2001). Likewise, nuclear splicing of PTC-containing mRNA and the position of PTC relative to intron sequences determine whether the PTC mRNA will be degraded upon trans- 
lation in the cytoplasm. Thus, splicing and translation are coordinated to ensure rapid elimination of PTC-containing mRNA.

Although the impact of nuclear history on cytoplasmic events controlling mRNA fate reveals a novel level of regulation of gene expression, the underlying mechanism is still unclear. There is an emerging role for nuclear-cytoplasmic shuttling RNA-binding proteins, including hnRNPs, that not only function in the nucleus but also control the fate of mRNAs in the cytoplasm (for review, see Shyu and Wilkinson 2000; Wilkinson and Shyu 2001; Dreyfuss et al. 2003; Le Hir et al. 2003). It has been proposed that some shuttling proteins associate with the mRNA in the nucleus and determine where the mRNA will be localized, its rate of translation, and/or its rate of decay in the cytoplasm (e.g., Matsumoto et al. 1998; Loflin et al. 1999; Kataoka et al. 2000, 2001; Kim et al. 2001; Le Hir et al. 2001a; Lykke-Andersen et al. 2001). This scenario provides an appealing explanation for how the nuclear history of mRNA influences the cytoplasmic fate of mRNA. It implies that nuclear import occurs before these shuttling proteins influence the fates of target mRNAs in the cytoplasm. However, this critical aspect of nuclear import has not been tested. Shuttling proteins exist in both the nucleus and the cytoplasm. Some of them may associate with target mRNAs in the cytoplasm (Afonina et al. 1998; Iborra et al. 2001; Chen et al. 2002; Thakurta et al. 2002; Atasoy et al. 2003; Huwiler et al. 2003; Tran et al. 2003). So it is also possible that some shuttling proteins exert their functions in the cytoplasm without first going into the nucleus, and that the proteins that actually accompany mRNAs from the nucleus to the cytoplasm serve only to export mRNAs.

Identification of hnRNP D, a heterogeneous nuclear ribonucleoprotein found in both nucleus and cytoplasm, as a RNA-stability regulatory protein provides a potential link between nuclear history and decay of normal cytoplasmic mRNA. The role of hnRNP D, also termed AUF1, in mRNA decay mediated by AU-rich elements (AREs) has been widely studied (e.g., Zhang et al. 1993; Larola et al. 1999; Loflin et al. 1999; Xu et al. 2001). hnRNP D functions as a mRNA-destabilizing factor in human erythroleukemic K562 cells and as a mRNA-stabilization factor in mouse NIH3T3 cells (Loflin et al. 1999; Xu et al. 2001). Also, hnRNP D participates in RNA turnover directed by the c-fos major coding region determinant (mCRD; Grosset et al. 2000). It was found that hnRNP D is an integral component of a multiprotein complex that is suggested to mediate the c-fos mCRD-directed mRNA decay. Ectopic expression of hnRNP D in NIH3T3 cells effectively blocks the mCRDmediated decay (Grosset et al. 2000).

In this study, we used the p37 isoform of hnRNP D and NIH3T3 cells to identify the functionally important domains of p37 and to test the role of shuttling in p37 function in cytoplasmic mRNA turnover. The results support that hnRNP D must travel to the nucleus before it can influence mRNA turnover in the cytoplasm and suggest a mechanism by which nuclear history influences cytoplasmic mRNA fate.

\section{RESULTS}

\section{Functional dissection of p37 structural domains}

We first dissected functionally critical domains of p37 to evaluate whether the nuclear localization domain and the RNA-binding and RNA-stabilization effector domains are distinct. Ectopic expression of hnRNP D in mouse NIH3T3 cells results in inactivation of two distinct decay pathways that target c-fos mRNA for rapid degradation, that is, the pathways involving the c-fos ARE and the c-fos mCRD (Grosset et al. 2000; Xu et al. 2001). We set out to identify hnRNP D structural domains that are important for antagonizing the ARE- and the mCRD-mediated rapid mRNA degradation in NIH3T3 cells. p37 was chosen for the study because, among the four isoforms of hnRNP D, it exhibits the most profound RNA stabilization effect in NIH3T3 cells (Xu et al. 2001).

The N-terminal domain, RNA-Recognition-Motif (RRM) I, RRMII, and the C-terminal domain were individually deleted from p37 to create truncated derivatives (Fig. 1A; $\Delta \mathrm{N}, \Delta \mathrm{I}, \Delta \mathrm{II}$, or $\Delta \mathrm{C})$. Expression of $\mathrm{p} 37$ and its truncated derivatives were driven by the tetracycline-regulated promoter system (tet-off) to obtain constitutive expression in the absence of tetracycline in a NIH3T3 stable cell line, termed B2A2 (Xu et al. 1998). A myc-epitope tag was fused to the $\mathrm{N}$ termini of all cDNA clones to facilitate evaluation of protein expression levels. We first examined the effects of p37 on the cytoplasmic decay of both a $\beta$-globin mRNA bearing the c-fos ARE (BBB + ARE mRNA) and a hybrid transcript containing the $\beta$-globin mRNA $5^{\prime}$ and $3^{\prime}$ UTRs and the $c$-fos protein-coding region including the $c$-fos mCRD (BFB; Fig. 1B) in the same cells. The transcription pulse driven by the $\mathrm{c}$-fos promoter allowed determination of mRNA decay kinetics without using transcription inhibitors (Shyu et al. 1991; Xu et al. 1998), thus avoiding potential RNA stabilization side effects. A control plasmid encoding a stable message, termed $\alpha$-globin/GAPDH, was included in the cotransfection to serve as an internal standard.

The results of time-course experiments (Fig. 2A,C) showed that ectopic expression of p37, and not control vector, effectively impeded the rapid decay of $B F B$ and $\mathrm{BBB}+\mathrm{ARE}$ mRNAs in the cytoplasm. Ectopic expression of the N-terminal, RRMI, or RMMII truncation mutants $(\Delta \mathrm{N}$, $\Delta \mathrm{I}$, or $\Delta \mathrm{II})$ had some stabilization effects on the BBB $+\mathrm{ARE}$ mRNA but had little effect on BFB mRNA decay. In contrast, the C-terminal truncation $(\Delta C)$ had little effect on the decay of either the BBB + ARE or BFB mRNA. Western blot analysis of cytoplasmic extracts from cells transfected in parallel experiments showed that the levels of the recombinant proteins were similar (Fig. 2B), except for the $\Delta \mathrm{N}$ 
A. hnRNP D p37 \& mutant derivatives:

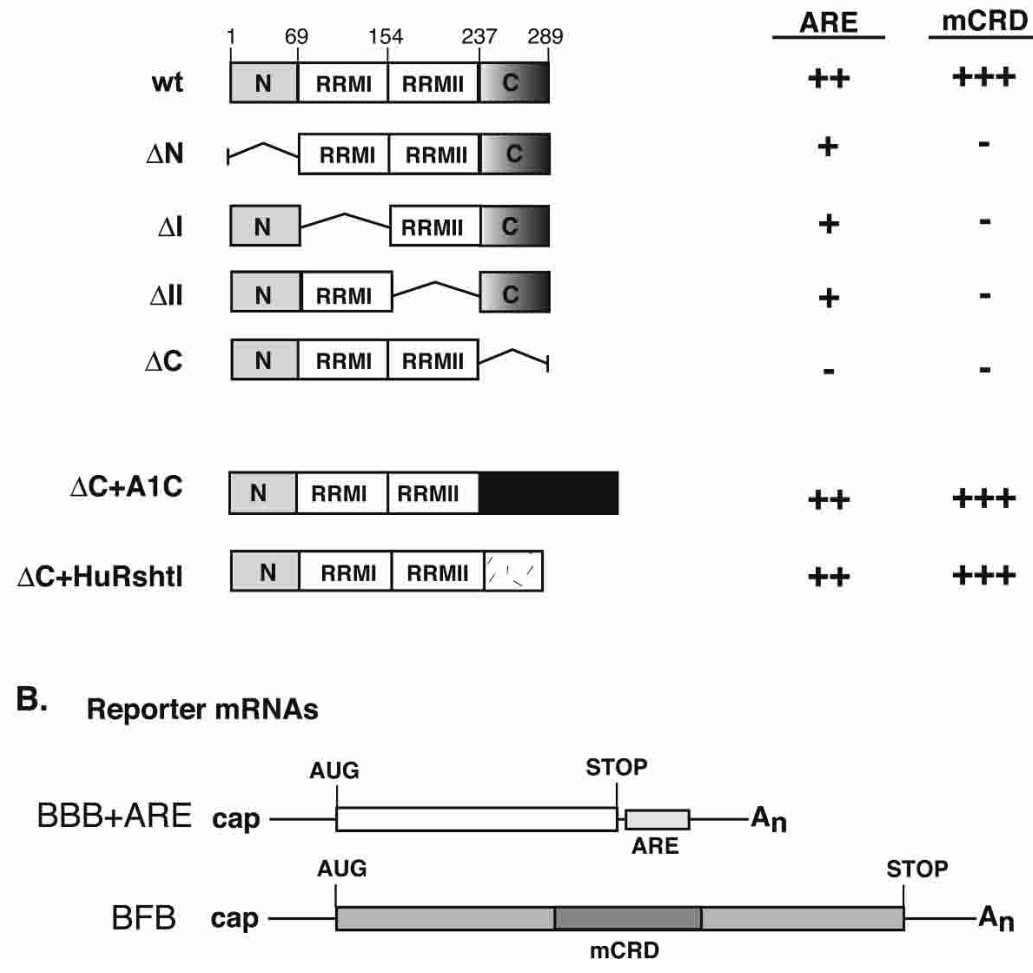

FIGURE 1. Physical maps of wild-type and mutant hnRNP D p37 proteins and BBB + ARE and BFB mRNAs and summary of the results from in vivo study. (A) Schematic diagram showing domain structure of human hnRNP D p37 isoform and its derivatives. Numbers above wt p37 depict amino acid positions (accession number: NM_031370). (Gray box marked with $\mathrm{N}) \mathrm{N}$-terminal domain of p37. (Open boxes) RNA recognition motifs (RRMI and RRMII) of p37. (Gradient gray box marked with C) C-terminal domain of p37. (Black box) hnRNP Al C-terminal domain. (Dotted box) HuR shuttling domain. (B) Physical map of $\beta$-globin mRNA containing the human c-fos AU-rich element (ARE) of instability (BBB + ARE) or proteincoding region (BFB). (Solid lines) $5^{\prime}$ and $3^{\prime}$ UTRs from rabbit $\beta$-globin mRNA. (Open rectangle) Protein-coding region from $\beta$-globin mRNA. (Small light gray rectangle) $c$-fos ARE. (Large gray rectangle) Protein coding region from c-fos mRNA. The c-fos major proteincoding-region determinant of instability (mCRD) is shown as a dark gray rectangle located in the middle of c-fos protein-coding region. Locations of the translation initiation (AUG) and translation termination (STOP) codons are indicated. (C) Summary of the relative RNA stabilization effect of the hnRNP D p37 isoform and its derivatives on the c-fos $3^{\prime}$ ARE- and mCRD-mediated mRNA decay. Details of the experiments are given in the legend to Figure 2.

mutant, which was considerably less abundant than the others. A subsequent experiment (see below, Fig. 4) showed that $\mathrm{N}$-terminal domain truncation enhances nuclear localization. Probing the same blot with antibody against $\alpha$-tubulin (Fig. 2B) showed that similar amounts of protein samples were loaded.

The N-terminal, RRMI, and RRMII domains, but not the C-terminal domain, had been identified as being necessary for high affinity binding for AREs when tested by in vitro gel-shift assays using bacteria-synthesized proteins (DeMaria et al. 1997). Thus, we were intrigued that $\mathrm{p} 37 \Delta \mathrm{C}$ had little effect on decay of the BBB + ARE mRNA instead of having a dominant stabilization effect. To further test whether p37 $\mathrm{C}$ made in NIH3T3 cells still retained the ability to bind the c-fos ARE, cell lysates containing ectopically expressed myctagged p37 or p37 $\Delta \mathrm{C}$ were used in gel mobility shift assays to compare their relative ARE-binding abilities. Antibody supershift assays using anti-myc-epitope tag antibody were performed to distinguish ARE-protein complexes formed by exogenous myc-tagged proteins, which were expressed in transfected cells $(-20 \%-25 \%$ of total cells), from complexes involving endogenous ARE-binding proteins. The results (Fig. 3) showed no appreciable difference between the supershifted complex formed with myctagged p37 and that formed with $\mathrm{p} 37 \Delta \mathrm{C}$, demonstrating that $\mathrm{p} 37 \Delta \mathrm{C}$ remains capable of binding the ARE in vitro. Together, our results showed that p37 $\mathrm{C}$, albeit capable of binding the ARE in vitro, has no effect on cytoplasmic mRNA turnover in vivo. These observations raised the question as to why p37 $\Delta \mathrm{C}$ cannot exert a stabilization effect in vivo.

\section{p37 is a shuttling protein with its nuclear import signal residing in the C-terminal domain}

A recent study showed that one hnRNP D-like protein contains a nuclear-cytoplasmic shuttling sequence in its C-terminal domain (Kawamura et al. 2002). This prompted us to look for a link between the RNA stabilization function and the shuttling function of hnRNP D itself. We first carried out immunofluorescence analysis of the subcellular distribution of ectopically expressed p37 isoform of hnRNP D and several derivatives in NIH3T3 cells. As shown in Figure 4, p37 was detected in both the nucleus and the cytoplasm, although mainly in the nucleus. Deleting the N-terminal domain resulted in strong staining of the nucleus, thus indicating an enhanced nuclear localization, consistent with the low level of $\mathrm{p} 37 \Delta \mathrm{N}$ detected in the cytoplasm by Western blotting (Fig. 2B). When either RRMI or RRMII was deleted from $\mathrm{p} 37$, the truncated proteins were detected in the cytoplasm as well as in the nucleus. By contrast, p37 $\mathrm{C}$ was detected nearly exclusively in the cytoplasm. This was confirmed by Western blot analysis showing little of the $\mathrm{p} 37 \Delta \mathrm{C}$ protein in the nuclear extract (Fig. 4B). Together, the results showed that the p37 $\mathrm{C}$, even though capable of binding ARE in vitro, was no longer localized in the nucleus and had no 
A
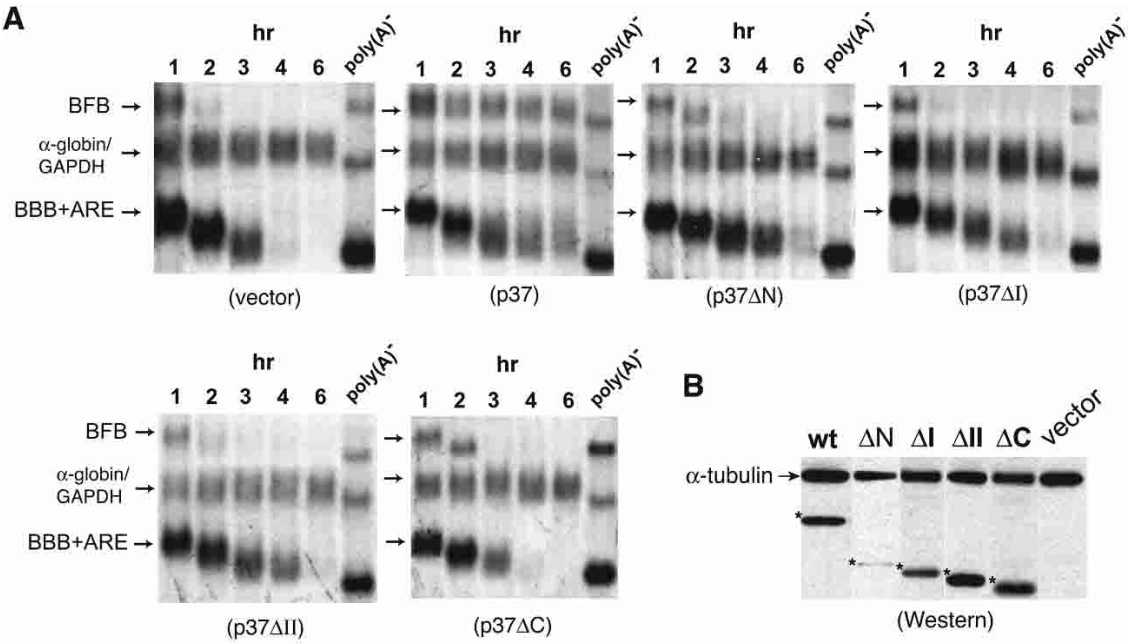

C
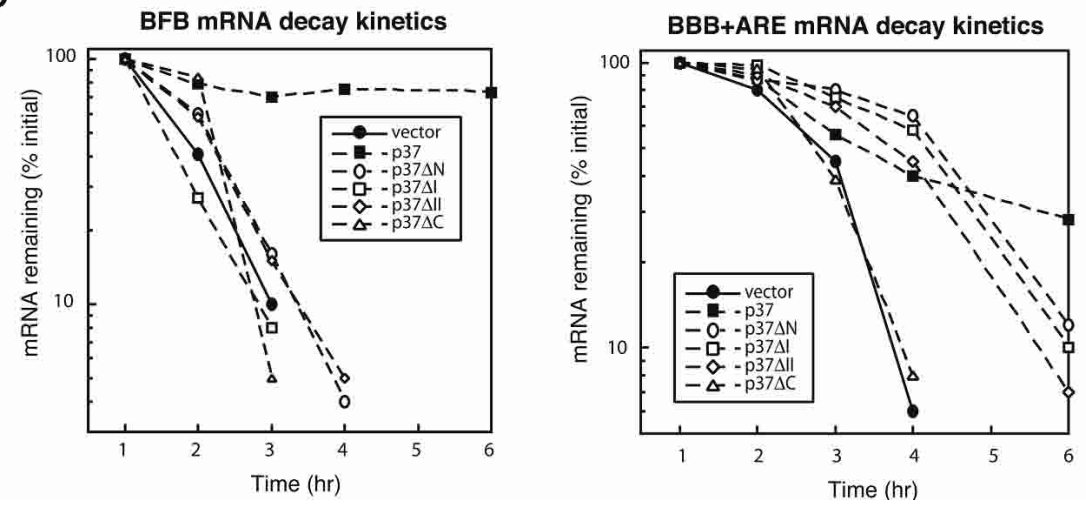

FIGURE 2. Dissection of protein domains of hnRNP D p37 functionally critical to its RNA stabilization effects. (A) RNA blots showing decay of $\beta$-globin mRNA containing the c-fos ARE $(\mathrm{BBB}+\mathrm{ARE})$ and decay of a hybrid mRNA (BFB) containing the c-fos protein-coding region. NIH $3 \mathrm{~T} 3 \mathrm{~B}_{2} \mathrm{~A}_{2}$ cells were transiently cotransfected with the test plasmids as indicated, a control plasmid (pSV $\alpha$-globin/GADH), and either pTet-myc-p37 or one of its derivatives (see Fig. 1A) or a control vector as indicated under each blot. Total cytoplasmic mRNA was isolated at various time intervals after serum stimulation of quiescent cells and analyzed by Northern blot analysis. Transcription of BFB and BBB + ARE mRNAs was driven by the serum-inducible c-fos promoter. The control mRNA ( $\alpha$-globin/GAPDH) was expressed constitutively and served as an internal standard. The times given at the top of each blot correspond to hours after serum induction. Poly $(\mathrm{A})^{-}$RNA was prepared in vitro by treating RNA samples from the 1-h time point with oligo(dT) and RNase $\mathrm{H}$. (B) Western blot analysis of the expression levels of p37 and its mutant derivatives in the cytoplasm. Cytoplasmic lysates prepared from NIH $3 \mathrm{~T} 3 \mathrm{~B}_{2} \mathrm{~A}_{2}$ cells transfected with plasmids containing myc-tagged $\mathrm{p} 37$, one of its derivatives, or control vector in parallel experiments were resolved on a SDS-12\% polyacrylamide gel. The blots were probed with specific antibodies against $m y c$-tag (9E10) and $\alpha$-tubulin (DM1A) as described in Materials and Methods. $(C)$ Semi-log plots showing the effects of p37 and its truncated derivatives on mRNA decay directed by the c-fos mCRD (left, BFB) or ARE (right, BBB + ARE). Quantitation of mRNA was obtained by scanning radioactive blots with an imager (Packard) and the data were plotted as a function of time.

effect on mRNA decay in vivo, suggesting that its cytoplasmic stabilization function required prior import into the nucleus.

To determine whether p37 can shuttle between the nucleus and the cytoplasm, and if it does, whether the Cterminal domain is necessary for shuttling, we employed heterokaryon shuttling analysis. Mouse NIH3T3 cells were first transiently transfected with myctagged $\mathrm{p} 37$ or $\mathrm{p} 37 \Delta \mathrm{C}$ cDNA and then fused with untransfected human HeLa cells in the presence of cycloheximide to block new protein synthesis. After fusion, the cells were cultured for another $3 \mathrm{~h}$ in the presence of cycloheximide. DAPI DNA staining was used to distinguish the mouse NIH3T3 cell nuclei from the human HeLa nuclei. In the heterokaryons, myc-tagged hnRNP C, expressed as a nuclear retention protein control (Nakielny and Dreyfuss 1996), remained in the NIH3T3 nucleus, whereas myc-tagged hnRNP Al, expressed as a shuttling protein control (Pinol-Roma and Dreyfuss 1992), was found in both NIH3T3 nuclei and HeLa nuclei (Fig. 5A). Like hnRNP A1, hnRNP D p37 was found in both the NIH3T3 and HeLa nuclei. In contrast, p37 $\Delta \mathrm{C}$ was absent from both nuclei and localized to the cytoplasm of fused cells, demonstrating that the C-terminal domain contains signal(s) required for both nuclear import and nuclear-cytoplasmic shuttling.

\section{The C-terminal domain of p37 can be replaced with shuttling domains from heterologous proteins without impeding p37's cytoplasmic RNA stabilization effect}

The above observations are consistent with the ideas that hnRNP D p37 needs to enter the nucleus before it can exert an RNA stabilization effect in the cytoplasm, and that the p37 C-terminal domain is required for RNA stabilization because it ensures nuclear localization. If this is the case, the ability of the $\Delta \mathrm{C}$ mutant to stabilize mRNA in the cytoplasm should be recovered by fusing on a heterologous shuttling domain as long as this domain can bring p $37 \Delta \mathrm{C}$ to the nucleus again. The $\mathrm{C}$-terminal domain of hnRNP A1, which contains the M9 motif, was chosen to test this possibility. The M9 motif contains shuttling signals for nuclear import and export (Izaurralde et al. 1997), but does not contain any sequences with significant homology to the p37 C-terminal domain. hnRNP Al was shown previously to redistribute to the cytoplasm upon osmotic shock of mammalian cells by sorbitol (van der Houven van Oordt et al. 2000). When we 


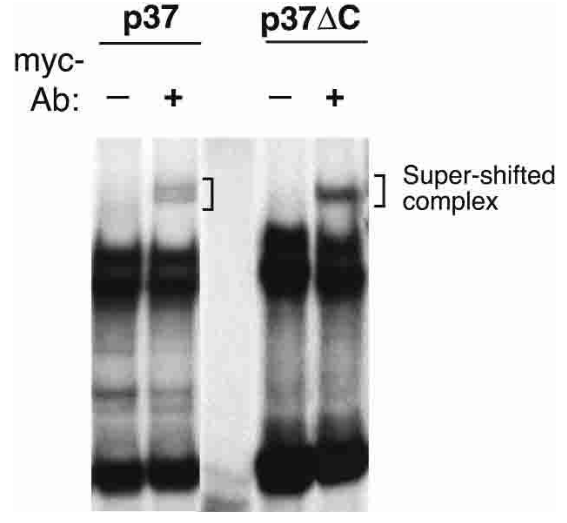

FIGURE 3. hnRNP D p37 without the C-terminal domain remains capable of binding c-fos ARE. Gel mobility shift analysis of interactions between ectopically expressed myc-tagged hnRNP D p37 or its Cterminal deletion mutant (p37 $\Delta \mathrm{C}$ ) and the c-fos ARE. ${ }^{32} \mathrm{P}$-labeled ARE RNA transcribed in vitro from a T3 promoter-driven template was incubated with cytoplasmic lysates from NIH $3 \mathrm{~T} 3 \mathrm{~B}_{2} \mathrm{~A}_{2}$ cells expressing myc-tagged hnRNP D p37 or p37 $\Delta$ C protein. The RNA-protein complexes were then digested with RNase T1. The digested mixtures were left alone $(-)$ or further incubated in the presence of the 9E10 monoclonal antibody against the myc-epitope tag (+ myc-Ab). The final reaction mixtures were resolved by electrophoresis in a native polyacrylamide gel. Antibody-supershifted complexes are indicated.

examined, by immunofluorescence microscopy, the subcellular distributions of endogenous hnRNP D and endogenous hnRNP A1 in NIH3T3 cells following sorbitol-induced osmotic shock (Fig. 5B), hnRNP Al demonstrated a significant increase in cytoplasmic accumulation; in contrast, there was no change observed in the distribution of endogenous hnRNP D. In addition, the actinomycin D-induced cytoplasmic accumulation observed with hnRNP Al (Pinol-Roma and Dreyfuss 1991) was not observed in hnRNP D (data not shown). Taken together, we conclude that the hnRNP A1 nuclear-cytoplasmic shuttling characteristics are distinct from those of hnRNP D in NIH3T3 cells.

The C-terminal domain of hnRNP A1 was then fused to $\mathrm{p} 37 \Delta \mathrm{C}$ to create a hybrid protein (p37 $\mathrm{C}+\mathrm{A} 1 \mathrm{C})$. As shown in Figure 4, A and B, the A1 shuttling domain helps p37DC to enter the nucleus again and the hybrid protein regains nuclear-cytoplasmic shuttling ability as demonstrated by heterokaryon experiments (Fig. 5A). We then determined the ability of p37 $\mathrm{C}+\mathrm{A} 1 \mathrm{C}$ to stabilize $\mathrm{BBB}+\mathrm{ARE}$ and $\mathrm{BFB}$ transcripts in time-course experiments. The results showed that ectopic expression of p37 $\mathrm{C}+\mathrm{A} 1 \mathrm{C}$ leads to stabilization of both the BBB + ARE and BFB mRNAs (Fig. 6A,C). Western blot analysis (Fig. 6B) confirmed similar levels of p37 $\Delta \mathrm{C}$ and $\mathrm{p} 37 \Delta \mathrm{C}+\mathrm{A} 1 \mathrm{C}$ protein expression in the cytoplasm and further showed that their subcellular distributions are consistent with those detected by immunofluorescence microscopy (Fig. 4A). A clean separation of the cytoplasmic extracts from the nuclear lysate fractions in the Western blot analysis was demonstrated by the staining pattern observed for a nuclear splicing factor, U1 70K, and a cytoplasmic protein, $\alpha$-tubulin. As a control to show that the mRNA stabilization effect was specific, ectopic expression of $\mathrm{HuR}$, another RRM-containing shuttling protein, only stabilized the $\mathrm{BBB}+\mathrm{ARE}$ mRNA and not the BFB transcript (Fig. $6 \mathrm{~A}, \mathrm{C})$.

To further substantiate the above result, we also tested the ability of the HuR shuttling domain (HuRshtl) to restore the nuclear localization and mRNA stabilization function of $\mathrm{p} 37 \Delta \mathrm{C}$. The basic hinge region connecting RRMII and RRMIII domains of HuR is known to be sufficient to confer nuclear-cytoplasmic shuttling on a heterologous nonshuttling protein (Fan and Steitz 1999). Importantly, HuR, hnRNP D and hnRNP Al shuttling domains share no sequence similarity. Both immunofluorescence microscopy and Western blot analysis showed that the p37 $\mathrm{C}+$ HuRshtl protein was present in the nucleus (Fig. 7A). As shown in Figure $7, \mathrm{~B}$ and $\mathrm{C}$, ectopic expression of the p37 $\mathrm{C}+$ HuRshtl protein resulted in significant stabilization of both
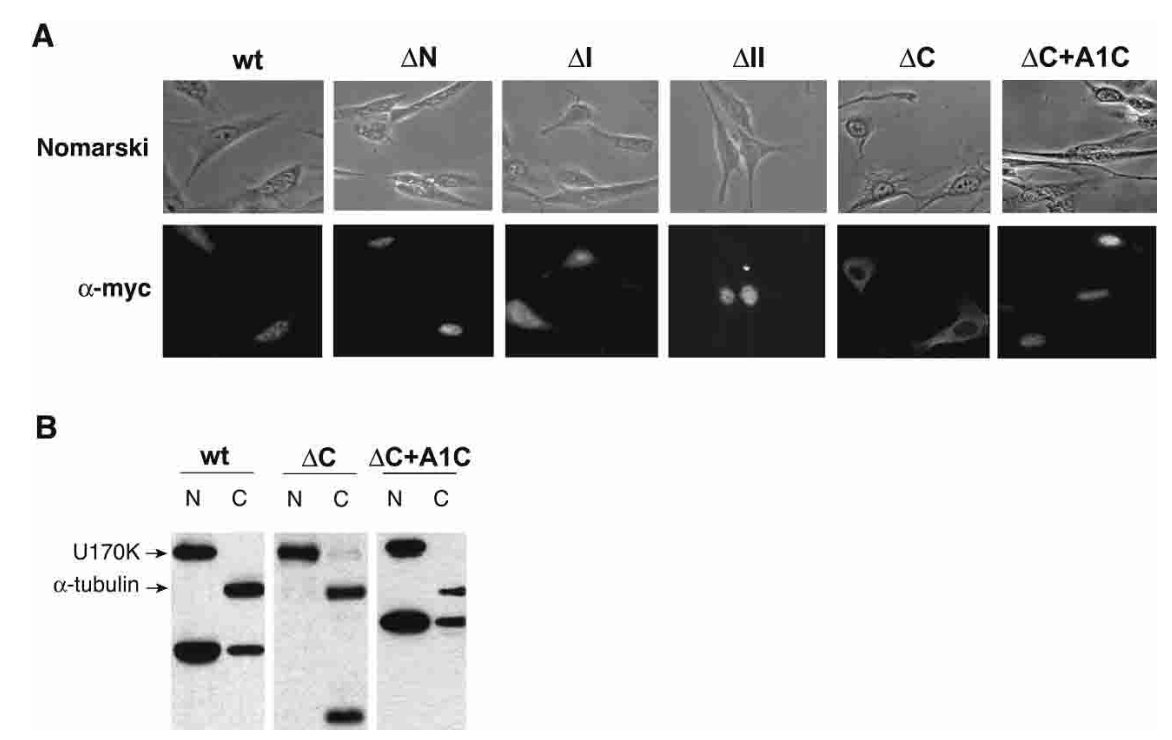

FIGURE 4. Subcellular distribution of human hnRNP D p37 and its derivatives in mouse NIH3T3 cells. (A) Indirect immunofluorescence microscopy study with a mAb against mycepitope tag (9E10) showing the subcellular distribution of hnRNP D p37 and its derivatives. Immunofluorescence microscopy was performed as described in Materials and Methods. Both phase contrast (depicted as Nomarski) and immunofluorescence (depicted as $\alpha$-myc) views are shown. (B) Western blot analysis. Cytoplasmic $(\mathrm{C})$ and nuclear $(\mathrm{N})$ lysates prepared from NIH $3 \mathrm{~T} 3 \mathrm{~B}_{2} \mathrm{~A}_{2}$ cells transfected with plasmids containing myc-tagged p37 or one of its derivatives were resolved on a SDS-12\% polyacrylamide gel. The blots were probed with the 9E10 MAb for myc-tagged target proteins, a control $\mathrm{mAb}$ against $\alpha$-tubulin for cytoplasmic lysate, and a control mAb against U1 70K for nuclear lysate as described in Materials and Methods. 
A

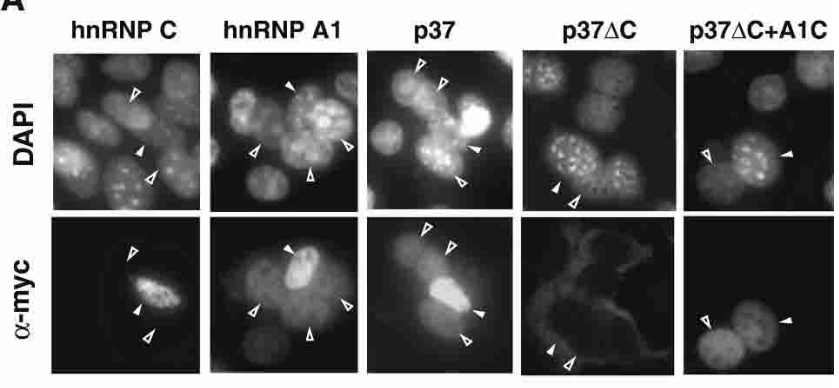

B

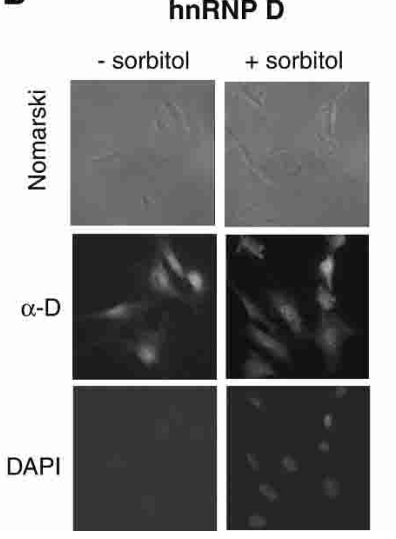

hnRNP A1

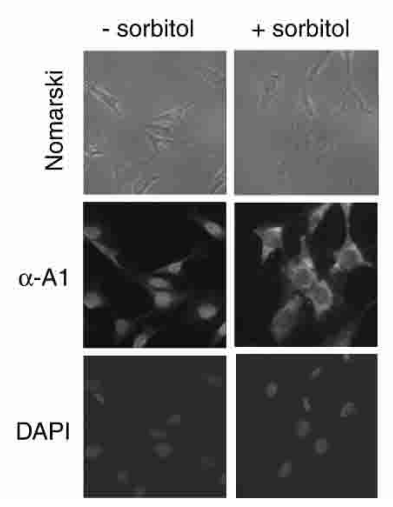

FIGURE 5. p37 is a nuclear-cytoplasmic shuttling protein and the nuclear import signal resides in the C-terminal domain. $(A)$ Heterokaryon analysis for protein shuttling. NIH3T3 $\mathrm{B}_{2} \mathrm{~A}_{2}$ cells were transfected with plasmids containing hnRNP C (control for nuclear, nonshuttling protein), hnRNP A1 (control for shuttling protein), p37, p $37 \Delta C$, or p $37 \Delta C+A 1 C$ for $40 \mathrm{~h}$. The cells were fused with HeLa cells and cultured in the presence of cycloheximide. Cell nuclei were viewed by DAPI staining. Target proteins were detected using the $9 \mathrm{E} 10 \mathrm{mAb}$ against myc-tag. Filled arrowheads indicate the NIH3T3 nuclei and open arrowheads depict HeLa nuclei. $(B)$ Indirect immunofluorescence microscopy showing that hnRNP D nuclear-cytoplasmic shuttling is different from that of hnRNP A1. To study the subcellular distribution of endogenous hnRNP D and hnRNP A1 in NIH3T3 cells under osmotic shock, NIH3T3 cells were cultured on coverslips in the absence (-sorbitol) or in the presence of $400 \mathrm{mM}$ sorbitol for $2 \mathrm{~h}$ (+sorbitol). Cells were fixed and stained as described in Materials and Methods. Both phase contrast (depicted as Nomarski) and immunofluorescence (depicted as $\alpha-\mathrm{D}$ or $\alpha-\mathrm{A} 1$ ) views are shown. Cell nuclei were viewed by DAPI staining.

$\mathrm{BBB}+\mathrm{ARE}$ and BFB mRNAs. Taken together, the observation that three different shuttling domains, sharing no sequence homology with each other, all restore the nuclear localization and concomitantly RNA stabilization function of $\mathrm{p} 37 \Delta \mathrm{C}$ supports the conclusion that nuclear import of hnRNP D is necessary before it can influence mRNA turnover in the cytoplasm.

\section{p37 nuclear import correlates with its ability to associate with target mRNAs}

To test whether the ability of nuclear import of p37 correlates with its ability to associate with target mRNAs, we

performed immunoprecipitation (IP) and RT-PCR analysis to determine whether p37, p37 $\mathrm{C}, \mathrm{p} 37 \Delta \mathrm{C}+\mathrm{A} 1$, and p37 $\triangle C+$ HuRshtl proteins associate with $B B B+A R E$ and BFB mRNAs in the nuclear and cytoplasmic fractions. NIH3T3 cells were transiently transfected with three plasmids: a test plasmid that produces myc-tagged p37 or one of its mutant derivatives and two reporter plasmids that produce $\mathrm{BBB}+\mathrm{ARE}$ and $\mathrm{BFB}$ mRNAs. Transfected cells were serum starved for $26 \mathrm{~h}$, stimulated with serum, and lysed $1 \mathrm{~h}$ later. Nuclear and cytoplasmic extracts were generated, and immunoprecipitations were performed under conditions that preserve RNPs. To enhance recovery of myc-tagged proteins, an anti-myc epitope antibody conjugated to agarose beads was used in the IP experiments. Bound materials were eluted, and protein and RNA were purified for analysis by Western blotting and RT-PCR, respectively. Western blotting of the cytoplasmic fractions (Fig. 8A) showed that a significant portion of the myctagged p37, p37 $\Delta \mathrm{C}, \mathrm{p} 37 \Delta \mathrm{C}+\mathrm{A} 1 \mathrm{C}$, and p37 $\mathrm{C}+$ HuRshtl proteins present in the input lysates was immunoprecipitated by the antibody. In contrast, cells transfected with a control vector did not show any signals. As another control to ensure that the IP material was specifically precipitated by the anti-myc antibody, the same blot was also probed with an antibody against an abundant cytoplasmic protein, $\alpha$-tubulin. The result showed that $\alpha$-tubulin was only detected in the input cytoplasmic extracts (lysate) and in the supernatants after immunoprecipitation (Fig. 8A, Ly and Af lanes) and not in the immunoprecipitates themselves (Fig. 8A, IP lanes). To avoid nonspecific amplification from transfected plasmid DNAs, RNA samples were subject to DNase I treatment prior to RT-PCR. The results of RT-PCR showed that the BBB + ARE and BFB mRNAs were present in IP materials from cells expressing p37, p37 $\Delta C+A 1 C$, and $\mathrm{p} 37 \Delta \mathrm{C}+\mathrm{HuRshtl}$ proteins, but were barely detected in the IP material of $\mathrm{p} 37 \Delta \mathrm{C}$, even though both transcripts were present in the input lysates containing ectopically expressed $\mathrm{p} 37 \Delta \mathrm{C}$. These results demonstrated that $\mathrm{p} 37 \Delta \mathrm{C}$ could not associate with target mRNAs in the lysate. Note that $\mathrm{p} 37 \Delta \mathrm{C}$ is the most abundantly expressed protein and was able to interact with in vitro synthesized ARE RNA substrate, when tested in the in vitro gel-shift assay (Fig. 3).

Western blotting of the nuclear fractions (Fig. 8B) showed that p37, p37 $\mathrm{C}+\mathrm{A} 1 \mathrm{C}$, and $\mathrm{p} 37 \Delta \mathrm{C}+\mathrm{HuRshtl}$ proteins were present in the nuclear fraction, whereas p37 $\Delta$ C was not. Detection of nuclear protein, U1 70K, in the input lysates and the supernatants after immunoprecipitations and not the immunoprecipitates themselves demonstrated the specificity of IP by the anti-myc antibody. The RT-PCR results showed that both the BBB + ARE and BFB mRNAs were detected in the IP materials from nuclear fractions of cells expressing p37, p37 $\mathrm{C}+\mathrm{A} 1 \mathrm{C}$, and p37 $\Delta C+$ HuRshtl proteins, but not from nuclei of cells expressing the control vector or $\mathrm{p} 37 \Delta \mathrm{C}$, demonstrating a nuclear association of the target mRNAs with p37, 
A

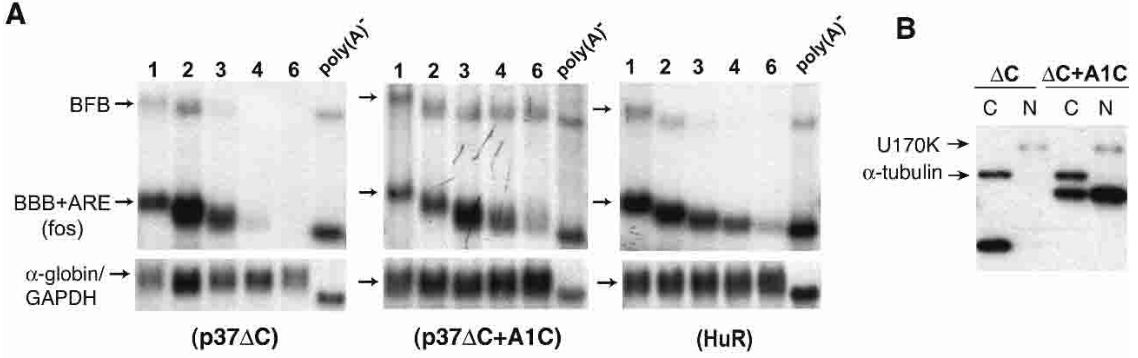

C

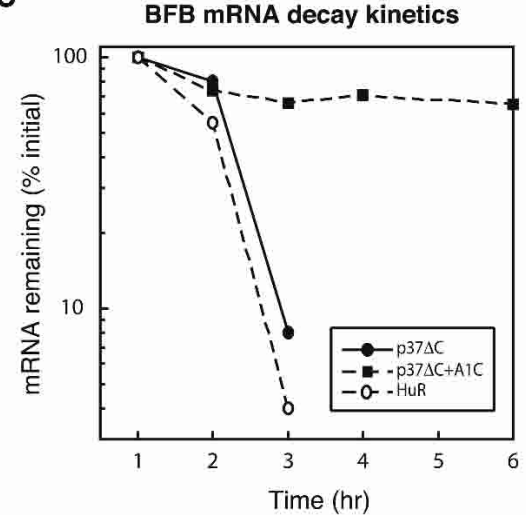

BBB+ARE mRNA decay kinetics

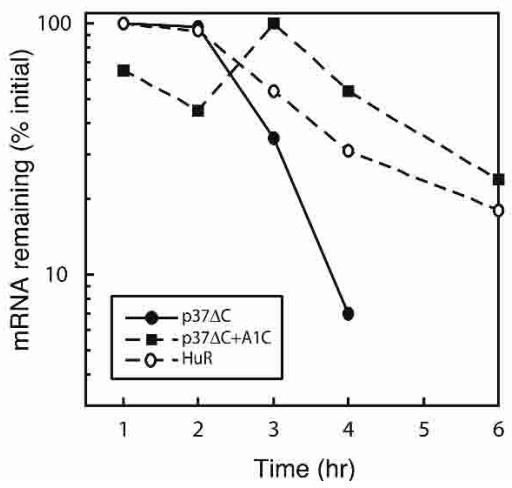

FIGURE 6. Restoring shuttling of $\mathrm{p} 37 \Delta \mathrm{C}$ concomitantly resumes its cytoplasmic RNA stabilization function. (A) RNA blots showing RNA stabilization effects of p37 $\mathrm{C}, \mathrm{p} 37 \Delta \mathrm{C}+\mathrm{A} 1 \mathrm{C}$, and HuR on decay of BBB + ARE and BFB mRNAs. RNA isolation, Poly(A) ${ }^{-}$RNA preparation and time-course experiments were carried out as described in the legend to Figure 2. The control mRNA ( $\alpha$-globin/GAPDH) was expressed constitutively and served as an internal standard. The times given at the top of each blot correspond to hours after serum induction. (B) Western blot analysis of $\mathrm{p} 37 \Delta \mathrm{C}$ and hybrid protein $\mathrm{p} 37 \Delta \mathrm{C}+\mathrm{AlC}$. Cytoplasmic (C) and nuclear $(\mathrm{N})$ lysates preparation, electrophoresis, and antibody information were as described in the legend to Figure 4. (C) Semi-log plots showing RNA stabilization effects of p37 $\Delta C$, p37 $\triangle \mathrm{C}+\mathrm{A} 1 \mathrm{C}$, and HuR on decay of BFB mRNA (left) and BBB + ARE mRNA (right). Quantitation of mRNA was obtained by scanning radioactive blots with an imager (Packard) and the data were plotted as a function of time.

$\mathrm{p} 37 \Delta \mathrm{C}+\mathrm{A} 1 \mathrm{C}$, and $\mathrm{p} 37 \Delta \mathrm{C}+\mathrm{HuRshtl}$ proteins. Taken together, our data suggested that nuclear import is required for p37's association with target mRNAs, supporting the notion that $\mathrm{p} 37$ associates with target mRNAs only in the nucleus and not in the cytoplasm and accompanies them to the cytoplasm where it can exert its cytoplasmic RNA stabilization effect.

\section{DISCUSSION}

It is becoming increasingly evident that events during mRNA biogenesis in the nucleus imprint some of the information required for subsequent localization, translation, and turnover of mRNA in the cytoplasm (Wolffe and Meric 1996; Shyu and Wilkinson 2000; Kim and Dreyfuss 2001; Maniatis and Reed 2002; Dreyfuss et al. 2003; Le Hir et al. 2003). A large part of this imprinting is a result of association with various shuttling and nonshuttling proteins during nuclear mRNA biogenesis, and some of the shuttling proteins are thought to accompany mature mRNAs into the cytoplasm in the form of mRNPs. For instance, Dreyfuss and coworkers (Pinol-Roma and Dreyfuss 1992) found that a subset of hnRNP proteins, associated with both pre-mRNA and mature mRNA populations in the nucleus, shuttle between nucleus and cytoplasm, suggesting that shuttling hnRNP proteins play a role in conveying the nuclear history of mRNA to cytoplasmic machinery controlling mRNA fates. Taken with the observation (Visa et al. 1996) that hnRNP Al homolog of Chironomus tentans accompanies mRNA exiting the nucleus via the nuclear pore complex, these studies raised the possibility that shuttling proteins associate with target mRNAs in the nucleus during mRNA biogenesis, travel with mRNAs to the cytoplasm where they continue to regulate mRNA function. This scenario gained support in some recent studies as well. For example, Ybox proteins, for example, FRGY2, which associates with maternal mRNAs transcribed in the nuclei of Xenopus laevis oocytes, are required for translational silencing of some maternal mRNAs in the cytoplasm (Matsumoto and Wolffe 1998). Nuclear history also seems to be conveyed by the exon-junction complex (EJC), a large complex of proteins that are deposited just upstream of exonexon junctions in mature mRNA after pre-mRNA splicing (e.g., Kataoka et al. 2000, 2001; Kim et al. 2001; Le Hir et al. 2001a,b; LykkeAndersen et al. 2001). Although the underlying mechanism remains nebulous, EJC proteins are thought to facilitate the export of some transcripts and to elicit nonsense-mediated mRNA decay in the cytoplasm. Thus, it has become a prevailing thought that the shuttling proteins accompanying mRNA to the cytoplasm continue to dictate the fate of mRNAs.

Our experiments here support a link between nuclear history of mRNA and its cytoplasmic lifespan established via the shuttling hnRNP D in a mammalian somatic cell line, mouse fibroblast NIH3T3 cells. We showed that when three different shuttling domains, including the C-terminal domain of p37 itself, the basic hinge region of $\mathrm{HuR}$, and the M9 shuttling motif of hnRNP A1, fuse to the nonshuttling part of p37 (p37 $\Delta \mathrm{C})$ to restore its ability to enter the nucleus, concomitantly, the respective proteins have the ability to block decay of both ARE-containing mRNA and mCRD-containing mRNAs in the cytoplasm. Moreover, our immunoprecipitation/RT-PCR experiments showed 
A

\section{p37 $\triangle \mathrm{C}+$ HuRshtl}

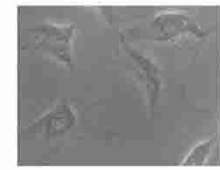

Nomarski

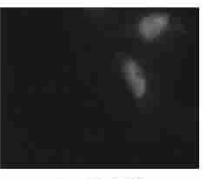

$\alpha-$ myc

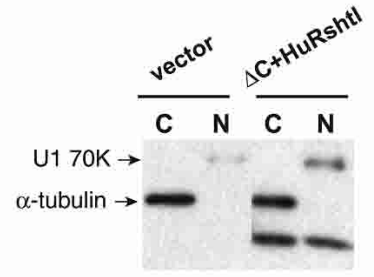

C

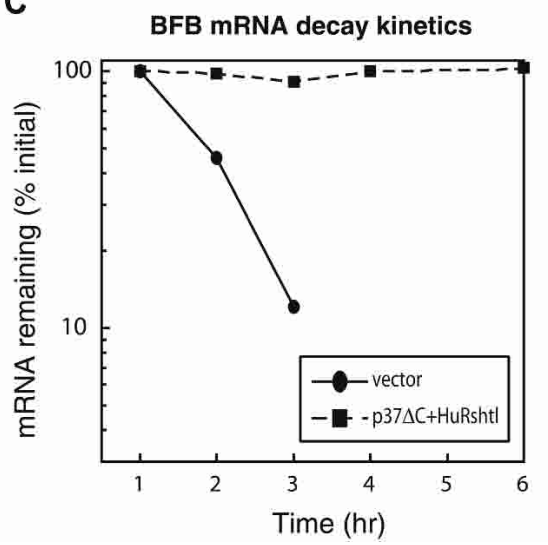

B
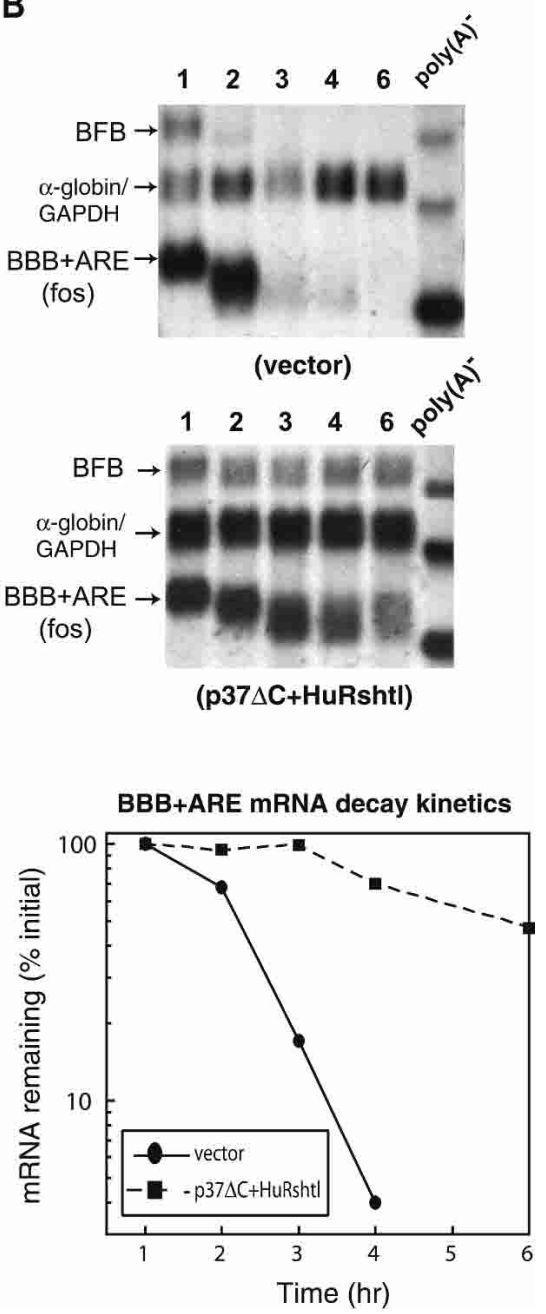

FIGURE 7. HuR shuttling domain, when fused to $\mathrm{p} 37 \Delta \mathrm{C}$, also restores its nuclear localization and cytoplasmic RNA stabilization function concomitantly. (A) Indirect immunofluorescence microscopy (left) and Western blot analysis (right) demonstrating the detection of the hybrid protein $\mathrm{p} 37 \Delta \mathrm{C}+\mathrm{HuRshtl}$ in both nucleus and cytoplasm. Experiments were carried out as described in the legend to Figure 4. (B) RNA blots showing stabilization effects of p37 $\mathrm{C}+$ HuRshtl on decay of BBB + ARE and BFB mRNAs. RNA isolation, Poly(A) ${ }^{-}$RNA preparation and time-course experiments were carried out as described in the legend to Figure 2 . The control mRNA ( $\alpha$-globin/GADH) was expressed constitutively and served as an internal standard. The times given at the top of each blot correspond to hours after serum induction. (C) Semi-log plots showing RNA stabilization effects of p37 $\Delta C+$ HuRshtl on decay of BFB mRNA (left) and BBB + ARE mRNA (right). Quantitation of mRNA was obtained by scanning radioactive blots with an imager (Packard) and the data were plotted as a function of time.

that p37 as well as the two hybrid shuttling proteins associate with target mRNAs in both the nucleus and the cytoplasm. It is of particular significance to find that even though the nonshuttling $\mathrm{p} 37 \Delta \mathrm{C}$ is expressed abundantly in the cytoplasm and remains capable of associating with the c-fos ARE in a gel-shift assay (Fig. 3), it does not associate with target mRNAs and has no effect on stabilizing these labile transcripts in vivo. Our data support the notion that p37 first enters the nucleus where it becomes associates with target mRNAs and travels with them to the cytoplasm where it blocks decay of the targets mRNAs. This also im- plies that p37 association with mRNAs in the nucleus interferes with assembly of a decay complex and/or subsequent recruitment of decay factors.

It is worth mentioning that HuR, another shuttling ARE-binding factor, behaves differently from hnRNP D p37. When the basic hinge region containing signals for shuttling was deleted from $\mathrm{HuR}$, the nonshuttling mutant protein remains capable of blocking ARE-mediated decay when ectopically overexpressed in the cytoplasm (Chen et al. 2002). Moreover, HuR redistribution to the cytoplasm correlates well with stabilization of ARE-containing mRNA (Atasoy et al. 2003; Huwiler et al. 2003; Tran et al. 2003), indicating that the association of this shuttling protein with a target ARE to exert its inhibitory effect occurs in the cytoplasm. This has prevented the shuttling HuR being used as a model system to address whether and how the shuttling function comes into play in cytoplasmic mRNA turnover.

A few possibilities may be envisaged to explain why only shuttling hnRNP D p37 can exert the mRNA stabilization function in the cytoplasm. One is that this p37 protein needs to associate with target mRNAs in the nucleus before the mRNAs bind to other destabilizing factors either in the nucleus, during nuclear export, or in the cytoplasm. Alternatively, it may be that posttranslational modification of p37 in the nucleus is necessary for its RNA-binding or protein-protein interactions. These two possibilities are not necessarily mutually exclusive, as modifications in the nucleus may give $\mathrm{p} 37$ a competitive advantage in competing with other proteins for binding to its target mRNAs and subsequently block their communication with cytoplasmic decay machinery. This interpretation is consistent with recent studies of hnRNP D p40 isoform and its phosphorylation state in THP-1 monocytic leukemia cells (Wilson et al. 2003a,b). These studies suggest a destabilizing function for phosphorylated p40 in AREmediated decay, and show that dephosphorylation of $\mathrm{p} 40$ correlates with stabilization of the ARE-containing mRNA in THP-1 cells. They suggest that posttranslational modifications play a role in modulating hnRNP D function. We have shown that ectopic expression of p40 in NIH3T3 cells has little effect on the ARE-mediated decay (Xu et al. 2001). 
A
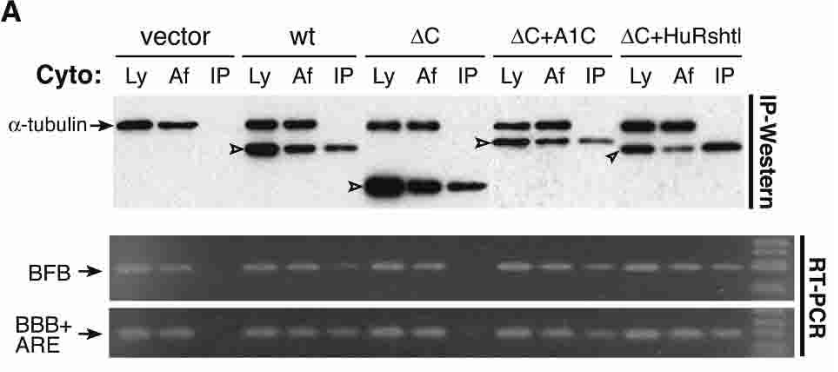

B
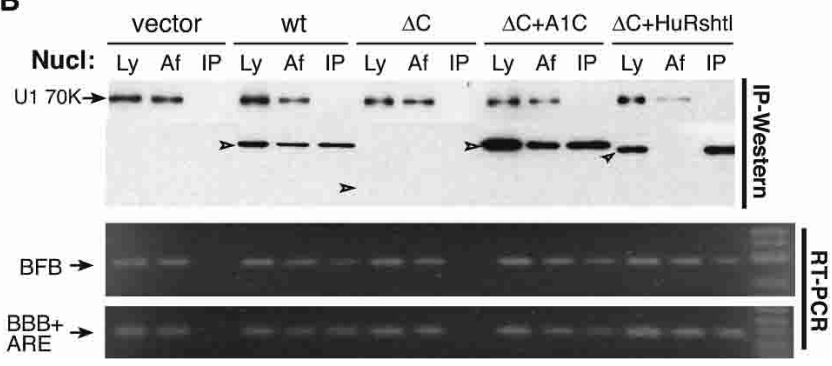

FIGURE 8. hnRNP D shuttling ability correlates with its ability to associate with target mRNAs. NIH $3 \mathrm{~T} 3 \mathrm{~B}_{2} \mathrm{~A}_{2}$ cells were transiently cotransfected with pBBB + ARE, pBFB, and either pTet-myc-p37, pTet-Myc-p37 $\Delta \mathrm{C}, \quad$ TTet-Myc-p37 $\Delta \mathrm{C}+\mathrm{AlC}$, pTet-Myc-p37 $\Delta \mathrm{C}+$ HuRshtl, or a control vector as described in Materials and Methods. Cytoplasmic ( $A$; Cyto) and nuclear $(B$; Nucl) lysates were prepared 1 $\mathrm{h}$ after serum stimulation of quiescent cells and then subjected to immunoprecipitation with anti-c-Myc mAb-conjugated agarose beads. We used $2.5 \mu \mathrm{g}$ each of original lysates (Ly), after immunoprecipitation (Af), and 1/10 volume of the immunoprecipitates (IP) for Western blot analysis (upper parts of panels $A$ and $B$ ) as described in the legend to Figure 4. RNA samples extracted from Ly, Af, and IP were digested with DNase I and used as the templates for RT-PCR reaction with primers specific to $\mathrm{BBB}+\mathrm{ARE}$ or BFB mRNA. RT-PCR products were loaded on a $2 \%$ (for a 412 -bp RT-PCR product amplified from $\mathrm{BFB}$ ) or $2.5 \%$ (for a 188-bp RT-PCR product amplified from $\mathrm{BBB}+\mathrm{ARE}^{\mathrm{c}-f o s}$ ) agarose gel that was subsequently stained with ethidium bromide (lower parts of panels $A$ and $B$ ). Three hundred nanograms of $\phi x 174$ DNA digested with Hinfl were loaded at the right lane of each agarose gel to serve as a size marker. Arrowheads in Western blots indicate the expected positions to which p37 and its derivative proteins migrate.

Thus it is tempting to speculate that up-regulation of p37 in NIH3T3 cells could, in theory, antagonize the p40 destabilizing function, leading to mRNA stabilization.

Although the nucleo-cytoplasmic shuttling activity of hnRNP D was first reported several years ago (Pinol-Roma and Dreyfuss 1991, 1992), the cDNAs were not cloned. It was not possible at the time to know the shuttling ability of individual isoforms of hnRNP D, particularly the least abundant p37 that sometime cannot be readily detected in the cytoplasm. We have now investigated the nucleo-cytoplasmic movement of p37 isoform and identified the domain that is necessary for its nuclear import. While our studies were in progress, Sarkar et al. (2003) reported the characterizations of nucleo-cytoplasmic shuttling function of all four isoforms of hnRNP D and identification of a shuttling domain in the $\mathrm{C}$ terminus. Consistent with their results, we also found that in p37 isoform, a nuclear import signal is located in the $\mathrm{C}$-terminal domain. In addition, our data show that unlike hnRNP Al, hnRNP D does not accumulate in the cytoplasm in response to osmotic stress, suggesting different routes and/or regulation of shuttling.

The bipartite arrangement of the structural domains of hnRNP D into two functionally distinct portions revealed by this study provides a useful system to study the link between nuclear history of mRNA and its cytoplasmic fate. The RNA-binding/RNA-stabilization effector domains (N terminus, RRMI, and RRMII) are directly involved in blocking degradation of target mRNAs, whereas the nuclear localization domain ( $\mathrm{C}$ terminus) is necessary to bring $\mathrm{p} 37$ to the nucleus, where it has the opportunity to associate with target mRNAs prior to leaving the nucleus. Our results also suggest that the effector part of p37 is involved in the ARE- and the mCRD-mediated decay in different manners. Deleting N-terminal domain, RRMI, or RRMII domain from p37 (Fig. 1) only partially affects its ability to block the c-fos ARE-mediated rapid mRNA decay. This is likely because those individual deletions only partially compromise the ARE-binding affinity and specificity of $\mathrm{p} 37$. This interpretation is consistent with in vitro RNA-binding studies using hnRNP D (AUF1) made in Escherichia coli, showing that deletion of any one of these domains only partially affects the ARE-binding affinity and all three domains are collectively required to achieve the highest affinity for ARE binding (DeMaria et al. 1997). On the other hand, these deletions abolish the ability of p37 to block rapid decay directed by the c-fos mCRD. Interestingly, hnRNP D does not directly interact with the mCRD RNA sequence (data not shown) yet it is one of the proteins that form a complex on the mCRD, termed a bridging complex (Grosset et al. 2000). Given that mCRD-containing mRNA can be co-immunoprecipitated along with p37, our data imply that p37 joins the bridging complex through protein-protein interactions with other component protein(s). Taken together, our results indicated that the $\mathrm{N}$-terminal domain and both RRMs together contribute to the full ARE stabilization effect exerted by p37 but are all indispensable for p37 to exert an inhibitory effect on the mCRD-mediated mRNA decay.

In summary, our data provide a series of experiments to test the notion that a nuclear-cytoplasmic shuttling protein associates with mRNA in the nucleus during its biogenesis, accompanies the mRNA to the cytoplasm, and there regulates its fate. The results suggest that entering the nucleus is a prerequisite before hnRNP D can stabilize mRNAs in the cytoplasm. It will be important to learn whether distinct roles in mRNA decay exist among the four isoforms of hnRNP D, and whether phosphorylation alters nuclear-cytoplasmic shuttling of p37 and its function in mRNA turnover. It also will be interesting to learn whether the actions of p37 hnRNP D apply to other shuttling proteins. One important implication of our results is that it may be critical to identify the shuttling proteins that associate with the 
RNA-regulatory elements in the nucleus in order to fully understand the regulation of cytoplasmic fate of mRNA by trans-acting factors and participating enzymes. Our study cautions that a RNA-fate determinant binding protein or complex identified in vitro using only cytoplasmic extracts may not reveal the real physiological function played by the determinant.

\section{MATERIALS AND METHODS}

\section{Plasmid construction}

The construction of plasmids pSV $\alpha 1 /$ GAPDH (Chen and Shyu 1994), pBBB + $\mathrm{ARE}^{\mathrm{c}-\text { fos }}$, pBFB (Shyu et al. 1989), pTet-Myc-Ovep, pTet-Myc-HuR (Peng et al. 1998), pTet-Myc-p37(hnRNP D; Xu et al. 2001), pT3ARE ${ }^{\text {fos }}$ (You et al. 1992), and pTet-Myc-HuRIII-tr (for construction of pTet-Myc-p37 $\mathrm{C}+$ HuRshtl; Chen et al. 2002) has been described previously. A series of in-frame deletion mutants derived from human hnRNP D p37 cDNA, including deletions of N-terminal domain ( $\Delta \mathrm{N}$; codons $1-69$ were deleted), RRMI $(\Delta \mathrm{I}$; codons $70-154$ were deleted), RRMII ( $\Delta \mathrm{II}$; codons 155-237 were deleted), or C-terminal domain ( $\Delta \mathrm{C}$, codons 238 289 were deleted), were created by PCR using pTet-Myc-p37 as template to generate plasmids pTet-Myc-p37 $\Delta \mathrm{N}$, pTet-Mycp37 II, pTet-Myc-p37 III, or pTet-Myc-p37 $\mathrm{C}$, respectively. The accession number for nucleotide sequence and predicted open reading frame of human hnRNP D is NM_031370. To construct pTet-Myc-p37 $\Delta \mathrm{C}+\mathrm{A} 1 \mathrm{C}$, an XmnI-SmaI fragment of pA1-CAThnRNPA1 (kindly provided by S. Riva [Instituto di Genetica Biochimica, Pavia, Italy]; Weighardt et al. 1995) containing the Cterminal domain of hnRNPA1 was inserted into the 3' Sall site (blunt-ended) of pTet-Myc-p37DC. To create pTet-Mycp37 $\Delta C+$ HuRshtl, a 245-bp fragment containing the shuttling domain of HuR, the basic hinge region connecting RRMII and RRMIII domains, and 10 amino acids of RRMIII of HuR (Chen et al. 2002), was amplified by standard PCR and was then used to replace the C-terminal domain of hnRNPA1 in pTet-Mycp $37 \Delta C+A 1 C$. The proper in-frame insertion of cDNAs for the above constructs were confirmed by DNA sequencing.

\section{RNA blot analysis and preparation of cytoplasmic and nuclear extracts}

Cell culture, DNA transfection, isolation of total cytoplasmic RNA, and Northern blot analysis were conducted as described previously (Shyu et al. 1996; Xu et al. 1998). Briefly, NIH3T3 $\mathrm{B}_{2} \mathrm{~A}_{2}$ cells stably harboring the tetracycline-repressible trans-activator (tTA) gene were transfected for $\sim 16 \mathrm{~h}$ with a total of $20 \mu \mathrm{g}$ of DNA as described in the legend to each figure. The cells were then serum starved for $25 \mathrm{~h}$, followed by stimulation with $20 \%$ of bovine serum (GIBCO BRL). Total cytoplasmic RNA was extracted at time intervals according to time-course experiments. Gene-specific DNA probes were prepared by the method of random oligonucleotide priming for Northern blot analysis. The ${ }^{32} \mathrm{P}$-labeled probes were produced by inclusion of $\left[\alpha-{ }^{32} \mathrm{P}\right] \mathrm{dCTP}(6000 \mathrm{Ci} /$ mmole; DuPont). For lysate preparations, one plate of transfected NIH3T3 $\mathrm{B}_{2} \mathrm{~A}_{2}$ cells (100-mm culture dish) from each parallel timecourse experiment was harvested for preparing cytoplasmic and nuclear extracts as described previously (Peng et al. 1998). Protein concentration was analyzed by the BCA protein assay reagent (Pierce). These samples were used in Western blot analysis, gel mobility shift and supershift assays, and immunoprecipitation/ RT-PCR experiments.

\section{Western blot analysis}

Proteins samples, including cytoplasmic extracts, nuclear lysates, or immunoprecipitates (see below), were resolved on a $12 \%$ SDSpolyacrylamide gel and analyzed using an ECL Western blotting kit (Amersham). The blots were probed with specific antibodies as described below. The antibody for myc-tag was obtained by collecting culture medium from hybridoma cells (9E10, ATCC) and was used at a 1:25 dilution. The purified monoclonal antibody against $\alpha$-tubulin (DM1A) was purchased from Sigma and was used at a 1:2500 dilution as a positive control for cytoplasmic protein preparations. A monoclonal antibody against the $\mathrm{U} 170 \mathrm{~K}$ (mouse IgG) was kindly provided by Sue Berget (Baylor College of Medicine, Houston, Texas) and was used at a 1:10 dilution as a positive control for nuclear protein preparations.

\section{Immunoprecipitation/RT-PCR analysis}

To perform immunoprecipitation/RT-PCR experiments, $200 \mu \mathrm{g}$ of cytoplasmic or nuclear extracts were precleared at $4^{\circ} \mathrm{C}$ with agarose beads without antibody (Sigma, S1638) for $90 \mathrm{~min}$ and then subject to immunoprecipitation with anti-c-Myc agarose (Sigma, A 7470), according to the manufacturer's protocol, at $4^{\circ} \mathrm{C}$ for $2 \mathrm{~h}$. One-tenth of the immunoprecipitates were used for Western blot analysis and the rest of the samples were extracted with Trizol (Invitrogen) for RNA preparation. After digestion with DNase I (Invitrogen, final concentration $0.5 \mathrm{U} / \mu \mathrm{L}$ ), each RNA sample was resuspended in $40 \mu \mathrm{L}$ of water, and $1 \mu \mathrm{L}$ of a 1:20 dilution was used for a $50-\mu \mathrm{L}$ RT-PCR reaction (Qiagen OneStep RT-PCR kit) using the following primers: 5'-AGCCCGCTCCGTGCCAGA CATG-3' (sense primer specific to the human c-fos ORF in BFB), 5'-ACTGAGATCCGTTTTATTGTG-3' (sense primer specific to the rabbit $\beta$-globin and $c$-fos $A R E$ junction and flanking regions in $\left.\mathrm{BBB}+\mathrm{ARE}^{\mathrm{c}-\text {-fos }}\right)$, and $5^{\prime}$-CCGGTGCGCAATGAAAATAAATTTC C-3' (antisense primer, specific to the rabbit $\beta$-globin 3' UTR, for both $\mathrm{BFB}$ and $\mathrm{BBB}+\mathrm{ARE}^{\mathrm{c}-f o s}$ ). The amount of RNA template used in each RT/PCR reaction at a given cycle was in a linear range, as confirmed by carrying out RT/PCR reactions with a series of different dilutions of the templates. A negative control (without template RNA) was included in all experiments. These experiments were performed at least twice and the results were reproducible. Four microliters of each RT-PCR product were loaded on a $2 \%$ (for a 412-bp RT-PCR product amplified from BFB) or 2.5\% (for a 188-bp RT-PCR product amplified from $\mathrm{BBB}+\mathrm{ARE}^{\mathrm{c}-\text { fos }}$ ) agarose (FMC; Nusieve GTG:Seakem = 3:1) gel, which was subsequently stained with ethidium bromide.

\section{Gel mobility shift assay and antibody supershift analysis}

The RNA probe synthesis, gel mobility shift assay, and antibody supershift assay were carried out as described previously (You et 
al. 1992). In vitro transcription using $\mathrm{pT} 3 \mathrm{ARE}^{\text {fos }}$ for transcribing c-fos ARE was carried out as described previously (You et al. 1992). Briefly, cytoplasmic lysate ( $8 \mu \mathrm{g}$ of protein) and ${ }^{32} \mathrm{P}$-labeled RNA $(1 \mathrm{ng})$ were incubated for $15 \mathrm{~min}$ at room temperature in a buffer containing $10 \mathrm{mM}$ HEPES ( $\mathrm{pH} 7.6$ ), $3 \mathrm{mM} \mathrm{MgCl}_{2}, 40 \mathrm{mM} \mathrm{KCl,} 2$ mM DTT, $10 \%$ glycerol, 0.5\% IGAPEL CA-630, $5 \mu \mathrm{g} / \mathrm{mL}$ heparin, and $200 \mathrm{ng} / \mathrm{mL}$ yeast total RNA. The volume of each reaction was $10 \mu \mathrm{L}$. Subsequently, unbound RNA was digested by including 0.6 $\mathrm{U}$ of RNase T1 (Calbiochem) for $20 \mathrm{~min}$ at room temperature. To perform gel mobility supershift analysis, $3 \mu \mathrm{L}$ of a monoclonal $\mathrm{Ab}$ against $m y c$-tag (9E10; Calbiochem) were added into the binding reaction following RNA-protein binding and RNase T1 digestion. The mixture was incubated for another $15 \mathrm{~min}$ at room temperature. RNA-protein complexes or RNA-protein-antibody complexes were resolved in $6 \%$ nondenaturing polyacrylamide gels in a cold room.

\section{Immunofluorescence microscopy study}

An indirect immunofluorescence study was conducted as described previously (Peng et al. 1998). Briefly, NIH 3T3 $\mathrm{B}_{2} \mathrm{~A}_{2}$ cells (Xu et al. 1998) were grown on coverslips in a $100-\mathrm{mm}$ culture dish containing $10 \mathrm{~mL}$ of $10 \%$ CS DMEM and transfected with plasmids expressing individual myc-tagged hnRNP D p37, one of the hnRNP D p37 derivatives, or one of the control plasmids as indicated in each figure. After $48 \mathrm{~h}$, cells were fixed with $100 \%$ methanol, permiabilized with $0.5 \%$ Triton X-100, and stained using MAb against myc-epitope tag (9E10) as primary antibody. To study the subcellular distribution of endogenous hnRNP D and hnRNP A1 in NIH3T3 cells under osmotic shock, NIH3T3 cells were cultured on coverslips in the absence or in the presence of $400 \mathrm{mM}$ sorbitol for $2 \mathrm{~h}$ (van der Houven van Oordt et al. 2000). Cells were fixed as described above and stained with antibody against hnRNP A1 (kindly provided by G. Dreyfuss [University of Pennsylvania, Philadelphia]) or against hnRNP D (kindly provided by Nancy Maizels [Yale University, New Haven, CT]) as primary antibody. The secondary antibody for anti-mouse- or anti-rabbit-IgG (purchased from Sigma) was coupled to FITC. All images were viewed and captured by a Spot-Digital camera (Diagnostics) and processed for publication at 300 d.p.i. using Adobe PhotoShop (7.0) software.

\section{Heterokaryon analysis}

Heterokaryon analysis was carried out using a protocol modified from the one kindly provided by Javier F. Caceres (MRC Human Genetics Unit, Edinburgh, Scotland; van der Houven van Oordt et al. 2000). Mouse NIH3T3 $B_{2} A_{2}$ cells were first grown on coverslips and transfected as described above. A three-fold excess of untransfected human HeLa cells resuspended in $10 \mathrm{~mL} \mathrm{10 \%} \mathrm{FBS} \mathrm{DMEM}$ containing $75 \mu \mathrm{g} / \mathrm{mL}$ cycloheximide was then added to the mouse NIH3T3 $\mathrm{B}_{2} \mathrm{~A}_{2}$ cells after $40 \mathrm{~h}$ of transfection (original medium was removed from $B_{2} A_{2}$ cells). The cells were incubated together for 3 $\mathrm{h}$ in the presence of $75 \mu \mathrm{g} / \mathrm{mL}$ cycloheximide and for another 30 min in the presence of $100 \mu \mathrm{g} / \mathrm{mL}$ cycloheximide. The coverslips were then washed with PBS, placed upside down onto a drop of prewarmed 50\% PEG (PEG 4000 in PBS), incubated for $2 \mathrm{~min}$, and washed thoroughly with PBS. After incubation in the presence of $100 \mu \mathrm{g} / \mathrm{mL}$ cycloheximide for another $3 \mathrm{~h}$, cells were fixed with
$100 \%$ methanol, permiabilized with $0.5 \%$ Triton $\mathrm{X}-100$, and stained using MAb against myc-epitope tag (9E10) as primary antibody. The secondary antibody for anti-mouse-IgG (purchased from Sigma) was coupled to FITC. All images were viewed and captured by a Spot-Digital camera (Diagnostics) and processed for publication at 300 d.p.i. using Adobe PhotoShop (7.0) software.

\section{ACKNOWLEDGMENTS}

We thank R. Kulmacz and M. Wilkinson for critical reading of the manuscript and their valuable comments. We thank the following colleagues for providing us with various materials and protocols: S. Berget for anti-U1 70K antibody, J.F. Caceres for heterokaryon protocol, G. Dreyfuss for the myc-hnRNP C and myc-hnRNP A1 plasmids and the monoclonal antibody against hnRNP A1, N. Maizels for anti-hnRNP D antibody, and S. Riva for the hnRNP A1 plasmid. Special thanks go to Y. Tao for technical assistance. This work was supported by a grant from the National Institutes of Health (GM 46454) to A.-B.S.

The publication costs of this article were defrayed in part by payment of page charges. This article must therefore be hereby marked "advertisement" in accordance with 18 USC section 1734 solely to indicate this fact.

Received December 12, 2003; accepted December 30, 2003.

\section{REFERENCES}

Afonina, E., Stauber, R., and Pavlakis, G.N. 1998. The human poly(A)binding protein 1 shuttles between the nucleus and the cytoplasm. J. Biol. Chem. 273: 13015-13021.

Atasoy, U., Curry, S.L., Lopez de Silanes, I., Shyu, A.-B., Casolaro, V., Gorospe, M., and Stellato, C. 2003. Regulation of eotaxin gene expression by TNF- $\alpha$ and IL- 4 through mRNA stabilization: Involvement of the RNA-binding protein HuR. J. Immunol. 171: 4369-4378.

Bourdon, V., Harvey, A., and Lonsdale, D.M. 2001. Introns and their positions affect the translational activity of mRNA in plant cells. EMBO Rep. 2: 394-398.

Chen, C.Y. and Shyu, A.B. 1994. Selective degradation of early-response-gene mRNAs: Functional analyses of sequence features of the AU-rich elements. Mol. Cell. Biol. 14: 8471-8482.

Chen, C.-Y.A., Xu, N., and Shyu, A.-B. 2002. Highly selective actions of HuR in antagonizing AU-rich element-mediated mRNA destabilization. Mol. Cell. Biol. 22: 7268-7278.

DeMaria, C.T., Sun, Y., Long, L., Wagner, B.J., and Brewer, G. 1997. Structural determinants in AUF1 required for high affinity binding to A + U-rich elements. J. Biol. Chem. 272: 27635-27643.

Dreyfuss, G., Kim, V.N., and Kataoka, N. 2003. Messenger-RNA-binding proteins and the messages they carry. Nat. Rev. Mol. Cell. Biol. 3: $195-205$.

Fan, X.C. and Steitz, J.A. 1999. HNS, a nuclear-cytoplasmic shuttling sequence in HuR. Proc. Natl. Acad. Sci. 95: 15293-15298.

Grosset, C., Chen, C.-Y.A., Xu, N., Sonenberg, N., Jacquemin-Sablon, H., and Shyu, A.-B. 2000. A mechanism for translationally coupled mRNA turnover: Interaction between the poly(A) tail and a c-fos RNA coding determinant via a protein complex. Cell 103: $29-40$.

Hentze, M.W. and Kulozik, A.E. 1999. A perfect message: RNA surveillance and nonsense-mediated decay. Cell 96: 307-310.

Huwiler, A., Akool, E.-S., Aschrafi, A., Hamada, F.M.A., Pfeilschifter, J., and Eberhardt, W. 2003. ATP potentiates IL-1b-induced MMP-9 expression in mesangial cells via recruitment of the ELAV protein HuR. J. Biol. Chem. 51758-51769.

Iborra, F.J., Jackson, D.A., and Cook, P.R. 2001. Coupled transcription 
and translation within nuclei of mammalian cells. Science 293: $1139-1142$.

Izaurralde, E., Jarmolowski, A., Beisel, C., Mattaj, I.W., Dreyfuss, G., and Fischer, U. 1997. A role for the M9 transport signal of hnRNP A1 in mRNA nuclear export. J. Cell Biol. 137: 27-35.

Kataoka, N., Yong, J., Kim, V.N., Velazquez, F., Perkinson, R.A., Wang, F., and Dreyfuss, G. 2000. Pre-mRNA splicing imprints mRNA in the nucleus with a novel RNA-binding protein that persists in the cytoplasm. Mol. Cell 6: 673-682.

Kataoka, N., Diem, M.D., Kim, V.N., Yong, J., and Dreyfuss, G. 2001. Magoh, a human homolog of Drosophila mago nashi protein, is a component of the splicing-dependent exon-exon junction complex. EMBO J. 20: 6424-6433.

Kawamura, H., Tomozoe, Y., Akagi, T., Kamei, D., Ochiai, M., and Yamada, M. 2002. Identification of the nucleocytoplasmic shuttling sequence of heterogeneous nuclear ribonucleoprotein D-like protein JKTBP and its interaction with mRNA. J. Biol. Chem. 277: 2732-2739.

Kim, V.N. and Dreyfuss, G. 2001. Nuclear mRNA binding proteins couple pre-mRNA splicing and post-splicing events. Mol. Cell 12: $1-10$.

Kim, V.N., Yong, J., Kataoka, N., Abel, L., Diem, M.D., and Dreyfuss, G. 2001. The Y14 protein communicates to the cytoplasm the position of exon-exon junctions. EMBO J. 20: 2062-2068.

Larola, G., Guesta, R., Brewer, G., and Schneider, R.J. 1999. Control of mRNA decay by heat shock-ubiquitin-proteasome pathway. Science 284: 499-502.

Le Hir, H., Gatfield, D., Braun, I.C., Forler, D., and Izaurralde, E. 2001a. The protein Mago provides a link between splicing and mRNA localization. EMBO Rep. 2: 1119-1124.

Le Hir, H., Gatfield, D., Izaurralde, E., and Moore, M.J. 2001b. The exon-exon junction complex provides a binding platform for factors involved in mRNA export and nonsense-mediated mRNA decay. EMBO J. 20: 4987-4997.

Le Hir, H., Nott, A., and Moore, M.J. 2003. How introns influence and enhance eukaryotic gene expression. Trends Biochem. Sci. 28: 215 220.

Loflin, P.A., Chen, C.-Y.A., and Shyu, A.-B. 1999. Unraveling a cytoplasmic role for hnRNP D in the in vivo mRNA destabilization directed by the AU-rich element. Genes \& Dev. 13: 1884-1897.

Lu, S. and Cullen, B.R. 2003. Analysis of the stimulatory effect of splicing on mRNA production and utilization in mammalian cells. RNA 9: 618-630.

Lykke-Andersen, J., Shu, M.D., and Steitz, J.A. 2001. Communication of the position of exon-exon junctions to the mRNA surveillance machinery by the protein RNPS1. Science 293: 1836-1839.

Maniatis, T. and Reed, R. 2002. An extensive network of coupling among gene expression machines. Nature 416: 499-506.

Maquat, L.E. and Carmichael, G.G. 2001. Quality control of mRNA function. Cell 104: 173-176.

Matsumoto, K. and Wolffe, A.P. 1998. Gene regulation by Y-box proteins: Coupling control of transcription and translation. Trends Cell Biol. 8: 318-323.

Matsumoto, K., Wassarman, K.M., and Wolffe, A.P. 1998. Nuclear history of a pre-mRNA determines the translational activity of cytoplasmic mRNA. EMBO J. 17: 2107-2121.

Nakielny, S. and Dreyfuss, G. 1996. The hnRNP C proteins contain a nuclear retention sequence that can override nuclear export signals. J. Cell Biol. 134: 1365-1373.

Nott, A., Meislin, S.H., and Moore, M.J. 2003. A quantitative analysis of intron effects on mammalian gene expression. RNA 9: 607-617.

Peng, S.-P., Chen, C.-Y., Xu, N., and Shyu, A.-B. 1998. RNA stabilization by the AU-rich element binding protein, HuR, an ELAV protein. EMBO J. 17: 3461-3470.

Pinol-Roma, S. and Dreyfuss, G. 1991. Transcription-dependent and transcription-independent nuclear transport of hnRNP proteins. Science 253: 312-314.

- 1992. Shuttling of pre-mRNA binding proteins between nucleus and cytoplasm. Nature 355: 730-732.
Sarkar, B., Lu, J.-Y., and Schneider, R.J. 2003. Nuclear import and export functions in the different isoforms of the AUF1/heterogeneous nuclear ribonucleoprotein protein family. J. Biol. Chem. 278: 20700-20707.

Shyu, A.B. and Wilkinson, M.F. 2000. The double lives of shuttling mRNA binding proteins. Cell 102: 135-138.

Shyu, A.-B., Greenberg, M.E., and Belasco, J.G. 1989. The c-fos mRNA is targeted for rapid decay by two distinct mRNA degradation pathways. Genes \& Dev. 3: 60-72.

Shyu, A.-B., Belasco, J.G., and Greenberg, M.G. 1991. Two distinct destabilizing elements in the c-fos message trigger deadenylation as a first step in rapid mRNA decay. Genes \& Dev. 5: 221-232.

Shyu, A.-B., Garcia-Sanz, J.A., and Mullner, E. 1996. Analysis of mRNA decay in mammalian cells. In The immunology methods manual (ed. I. Lefkovits), pp. 450-462. Academic Press, London.

Thakurta, A.G., Yoon, J.H., and Dhar, R. 2002. Schizosaccharomyces pombe spPABP, a homologue of Saccharomyces cerevisiae Pablp, is a non-essential, shuttling protein that facilitates mRNA export. Yeast 19: 803-830.

Tran, H., Maurer, F., and Nagamine, Y. 2003. Stabilization of urokinase and urokinase receptor mRNAs by HuR is linked to its cytoplasmic accumulation induced by activated mitogen-activated protein kinase-activated protein kinase 2. Mol. Cell. Biol. 23: 71777188 .

van der Houven van Oordt, W., Diaz-Meco, M.T., Lozano, J., Krainer, A.R., Moscat, J., and Caceres, J.F. 2000. The MKK(3/6)-p38-signaling cascade alters the subcellular distribution of hnRNP Al and modulates alternative splicing regulation. J. Cell Biol. 149: 307-316.

Visa, N., Alzhanova-Ericsson, A.T., Sun, X., Kiseleva, E., Björkroth, B., Wurtz, T., and Daneholt, B. 1996. A pre-mRNA-binding protein accompanies the RNA from the gene through the nuclear pores and into polysomes. Cell 84: 253-264.

Weighardt, F., Biamonti, G., and Riva, S. 1995. Nucleo-cytoplasmic distribution of human hnRNP proteins: A search for the targeting domains in hnRNP A1. J. Cell Sci. 108: 545-555.

Wilkinson, M.F. and Shyu, A.B. 2001. Multifunctional regulatory proteins that control gene expression in both the nucleus and the cytoplasm. Bioessays 23: 775-787.

Wilson, G.M., Lu, J., Sutphen, K., Suarez, Y., Sinha, S., Brewer, B., Villanueva-Feliciano, E.C., Ysla, R.M., Charles, S., and Brewer, G. 2003a. Phosphorylation of p40AUF1 regulates binding to A + Urich mRNA-destabilizing elements and protein-induced changes in ribonucleoprotein structure. J. Biol. Chem. 278: 33039-33048.

Wilson, G.M., Lu, J., Sutphen, K., Sun, Y., Huynh, Y., and Brewer, G. 2003b. Regulation of A + U-rich element-directed mRNA turnover involving reversible phosphorylation of AUF1. J. Biol. Chem. 278: 33029-33038.

Wilusz, C.J., Wang, W., and Peltz, S.W. 2001. Curbing the nonsense: The activation and regulation of mRNA surveillance. Genes \& Dev. 15: 2781-2785.

Wolffe, A.P. and Meric, F. 1996. Coupling transcription to translation: A novel site for the regulation of eukaryotic gene expression. Int. J. Biochem. Cell Biol. 28: 247-257.

Xu, N., Loflin, P., Chen, C.-Y.A., and Shyu, A.-B. 1998. A broader role for AU-rich element-mediated mRNA turnover revealed by a new transcriptional pulse strategy. Nucleic Acids Res. 26: 558-565.

$\mathrm{Xu}, \mathrm{N}$., Chen, C., and Shyu, A. 2001. Versatile role for hnRNP D isoforms in the differential regulation of cytoplasmic mRNA turnover. Mol. Cell. Biol. 21: 6960-6971.

You, Y., Chen, C.Y., and Shyu, A.B. 1992. U-rich sequence-binding proteins (URBPs) interacting with a 20 -nucleotide U-rich sequence in the $3^{\prime}$ untranslated region of c-fos mRNA may be involved in the first step of c-fos mRNA degradation. Mol. Cell. Biol. 12: 2931-2940.

Zhang, W., Wagner, B.J., Ehrenman, K., Schaefer, A.W., DeMaria, C.T., Crater, D., DeHaven, K., Long, L., and Brewer, G. 1993. Purification, characterization, and cDNA cloning of an AU-rich element RNA-binding protein, AUF1. Mol. Cell. Biol. 13: 76527665 . 

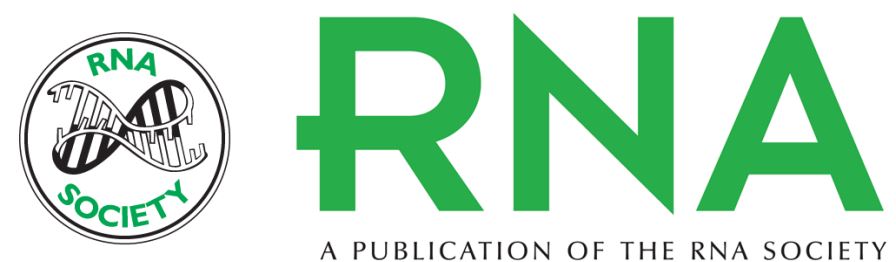

A PUBLICATION OF THE RNA SOCIETY

\section{Functional dissection of hnRNP D suggests that nuclear import is required before hnRNP D can modulate mRNA turnover in the cytoplasm}

CHYI-YING A. CHEN, NIANHUA XU, WENMIAO ZHU, et al.

RNA 2004 10: 669-680

References This article cites 48 articles, 34 of which can be accessed free at:

http://rnajournal.cshlp.org/content/10/4/669.full.html\#ref-list-1

License

Email Alerting Receive free email alerts when new articles cite this article - sign up in the box at the

Service top right corner of the article or click here.

To subscribe to $R N A$ go to:

http://rnajournal.cshlp.org/subscriptions 